\title{
Narratives in conflict and the limits on the interpreter's agency: A case study from the UN Peacekeeping mission in Lebanon
}

\author{
Yolanda Moreno-Bello \\ CETAPS, Universidade Nova de Lisboa \\ Yolandamorenobello@gmail.com \\ https://orcid.org/0000-0002-9106-6325
}

\begin{abstract}
This article presents a socio-linguistic analysis of interpreting in conflict zones and paints a picture of the limits on the interpreter's agency when working in the field. It focuses on the interpreter's behaviour towards cultural and linguistic barriers in communication between foreign military personnel and the civilian population in Lebanon. The aim is to analyse the level of agency that the interpreter has when working in a military deployment, taking into account the context and the narrative features that require mediation. Data were gathered through interviews with interpreters in Lebanon and analysed by applying narrative theory. Knowing and appreciating both the theoretical context and the linguistic and cultural barriers identified through the analysis are fundamental to understanding the difficult role that the interpreter-mediator plays in conflict settings and to reflecting on interpreter training that is appropriate to this context.
\end{abstract}

Keywords: intercultural mediation; military context; interpreting training; narratives; agency

\section{Introduction}

This article presents the findings of a socio-linguistic analysis of interpreting in conflict zones. Specifically, it focuses on the role of the war interpreter and the limits placed on the interpreter's agency while working between the military personnel and the civilian population. Considering the complex nature of interpreting in conflict zones and the general lack of awareness by the parties involved in this setting regarding those limits, this research studied the way in which the implications of intercultural mediation (or a lack of it) can disrupt communication in this context. In fact, this article is based on the assumption that communication is essential in any type of conflict and that strategies for achieving effective communication must go beyond language barriers, facilitating understanding and providing culturally appropriate messages (Federici \& O'Brien, 2019). The consequences of any breach of communication in conflict settings can vary from misinformation, a delay in acting and a denial of human rights to conflict escalation. This article accordingly reflects on the limits on the interpreter's agency to negotiate narratives in conflict situations when working in military deployments, in order to influence interpreters' training in this specific context. 
Moreno-Bello, Y. (2021). Narratives in conflict and the limits on the interpreter's agency: A case study from the UN Peacekeeping mission in Lebanon. Linguistica Antverpiensia, New Series: Themes in Translation Studies, 20, 94-114.

It is my contention that the limits on the interpreter's agency act as a barrier to intercultural mediation and that this has direct consequences on the individuals affected by the multiple, continuous and interconnected effects of a disruptive event. This article therefore organizes its objectives as follows: first, to identify the linguistic and cultural barriers encountered in conflict zones, and to classify them as indicators of the narrative features previously studied by Baker (2006); second, to evaluate the degree of agency the interpreter has when analysing their decisions in specific situations in military deployments.

Limiting the sample to interpreters who have worked in Lebanon and with United Nations Interim Force in Lebanon (UNIFIL), the article describes and discusses the findings from a broader project. ${ }^{i}$ The initial study consisted of an interview-based project that sampled the work of 12 freelance interpreters (working for NGOs, journalists and the military) and five members of the UNIFIL at the Cervantes Base where the Parachute Infantry Brigade was deployed at the time of the research. Owing to length constraints, I selected only 7 of the 17 interviews that disclosed the information most relevant to this particular study. The interviewees for this final selection were four locally recruited interpreters hired to work for the army at some point in their lives and three military interpreters. The interpreters were Lebanese and Spaniards who were living in Lebanon when the study took place. The interviews were collected in 2016. At that time Lebanon was not engaged in war, but tensions between Hezbollah and Israel were running high and several attacks occurred in the capital and other areas of Lebanon. The main aim of the UN peacekeeping mission in Lebanon was, and still is, to monitor the cessation of hostilities between Hezbollah and Israel and to accompany and assist the Lebanese Armed Forces (LAF) in the south of the country and along the separation between the two states, the so-called Blue Line. The mission also guarantees humanitarian access to civilian populations and the voluntary and safe return of displaced persons."i

Ruiz Rosendo and Persaud (2018) describe the role of interpreters in peacekeeping missions:

The complexity of interpreting activity in PKOs (Peacekeeping Operations) lies in the fact that interpreters have to cope with the challenges that come with an operation that combines military and civilian expertise, as well as the enormous challenges that are encountered in a stateor peace-building process, which entails covering a wide range of contexts, from low-level and informal conversations to mid-level conversations in safe environments and triadic negotiations in tense situations. (p. 3)

In this encounter between the civilian population and the arriving foreign military personnel, the mediating role of the interpreter acquires particular significance due to the circulation of competing narratives about the conflict (Moreno-Bello, 2021). The interpreter working with a peacekeeping mission is caught between a series of potentially divergent narratives that result from in-group norms, genres, particularities and other cultural aspects in relation to the context, such as west vs east, foreign vs local, and military vs civilian (Hoedemaekers \& Soeters, 2009, p. 348). Using the interpreters' accounts as qualitative data, I examined their agency in all these competing narratives when interpreting in interlinguistic encounters between civilians and military personnel. 
Moreno-Bello, Y. (2021). Narratives in conflict and the limits on the interpreter's agency: A case study from the UN Peacekeeping mission in Lebanon. Linguistica Antverpiensia, New Series: Themes in Translation Studies, 20, 94-114.

To ascertain the perception of the interpreter's agency in these settings, the article first provides an essential, yet by no means comprehensive, overview of the theoretical context of intercultural mediation in conflict zones. The overview is fundamental to emphasizing the active role the interpreter plays as a mediator and to understanding the fundamental concerns when considering the complex nature of interpreting in conflict situations. Second, this contribution explains the methods adopted to collect evidence of the interpreters' activities described in this article. Third, I scrutinize the interpreter's awareness of the mediation process involved. I do so by considering the interpreters' limitations according to allowed and possible behaviour in the given situational contexts. Finally, I focus on evaluating the interpreters' degree of agency vis-à-vis their deployment and operations in conflict zones. This evaluation is carried out against the backdrop of cultural and linguistic interferences that require mediation.

This research was carried out by following a qualitative interviewing method of research into the experiences and agency of conflict interpreters. The article is forthright about the disruptions to intercultural communication in situations of armed conflict. It states from the outset that these disruptions operate as barriers to the intercultural mediation that interpreters are often thought to be able to provide in contexts of international intervention. This possibly has direct consequences for the way interpreters think about their roles and themselves. Ethical constraints were imposed to protect participants' disclosures in their work environment, especially in the case of the interpreters working internally for the army. None of the participants was forced to answer any specific question, or to provide their names, and any further data that may help to identify them have been omitted.

\section{Intercultural mediation and interpreting in conflict zones}

The study discussed here rests on two crucial concepts: culture and interpreting in conflict zones. They are succinctly discussed with the purpose of providing a working conceptualization that rests on the most directly relevant principles behind the two. On the one hand, culture is a fundamental feature because of its relationship with language and, in addition, the type of interpreting involved in mediated encounters has an impact in intercultural interactions.

\subsection{Intercultural mediation}

Katan $(2009$, p. 74$)$ stresses how "intercultural communication" is a term coined by Hall and Hall (1959) to refer to the misunderstandings that occurred when US departmental administrators tried to communicate with Native Americans. These occurred as a result of "patterned factors" that were "silent", "hidden" or "unconscious" and not directly reflected in language. The interaction between a foreign government institution and the local population is relevant to our study because of the asymmetry and cultural clash of encounters in the context of UN peacekeeping in Lebanon. This type of communication involved cultural differences (Katan, 2009, p. 74) and it is a key concept implied in intercultural mediation since the main task that the mediator performs is "to negotiate the various signals, contexts, and stances" (Katan, 2009 , p. 88) involved in the communicative act, as explained by Taft (1981): 
Moreno-Bello, Y. (2021). Narratives in conflict and the limits on the interpreter's agency: A case study from the UN Peacekeeping mission in Lebanon. Linguistica Antverpiensia, New Series: Themes in Translation Studies, 20, 94-114.

A cultural mediator is a person who facilitates communication, understanding and action between persons or groups who differ with respect to language and culture. The role of the mediator involves interpreting the expressions, intentions, perceptions and expectations of each cultural group to the other, that is, by establishing and balancing the communication between them. (p. 53)

Nida's (2001, p. 26) examples of the relationship between culture and communication pertain to the different organization of the value systems of each culture, as reflected in the different types of language exchange. Precisely because the different values are embedded in different culture-dense terminology, cross-cultural and interlingual communication is prone to a higher degree of misunderstandings than monolingual interactions. The concept of "intercultural mediation" is therefore fundamental in the communication between people from different cultures who have different perceptions, different values and different semiotic representations of these values.

Owing to the nature of the setting, consecutive interpreting is mostly used to communicate between the parties involved. In this type of interpreting, differentiating between settings and work situations is essential to understanding the interpreter's role. On the one hand, interpreting scholarship emphasizes that a high level of cultural awareness and specific cultural knowledge are required skills of interpreters (Angelelli, 2004; Wadensjö, 2008); some scholars categorically suggest that any form of interpretation implies mediation between languages and cultures (Pöchhacker, 2008, p. 14). However, there is no agreement regarding its specific application to different work settings and contexts; and the notions of neutrality become particularly complex in this type of setting. Therefore, a mediator might be useful specifically for their intercultural knowledge, which can clarify any differences and perceptions that may result in misunderstandings in specific contexts. In this sense, we observed the level of agency by focusing on the interpreter's intervention, as mediator, where the interpreter tends to (or is expected to) add contextual information in order to avoid misunderstandings or asymmetry between participants.

Considering the objectives of this article, I focus only on the need for intercultural mediation and on the characteristics applicable to the work context of interpreters in conflict zones. in doing so, I highlight the limitations on the interpreter's agency to act accordingly, starting with the work of Moreno-Bello (2017).

\subsection{Agency of the interpreter in conflict zones}

The operational working conditions of military interpreters are characterized by the immediacy of danger, the interpreters' lack of training, the interferences involved and "the great deal of meaning that words can acquire in warlike or conflict context" (Moreno-Bello, 2017). In this sense, Angelelli (2003, p. 16) emphasizes the importance of the interpreter's awareness of their mediating role and that the importance of facilitating communication, as a cornerstone of interpreting interactions, is to enable the transfer of meaning regardless of the situational contexts in which the interaction takes place.

In this regard, the ground-breaking InZone research project (Moser-Mercer et al., 2014) and its approach to multilingual communication in communities affected by conflict is worth 
Moreno-Bello, Y. (2021). Narratives in conflict and the limits on the interpreter's agency: A case study from the UN Peacekeeping mission in Lebanon. Linguistica Antverpiensia, New Series: Themes in Translation Studies, 20, 94-114.

mentioning. This project stresses the interpreter's involvement in the development of conflict escalation and/or de-escalation and highlights the linkages between quality interpreting in conflict zones, protection and ethical decision-making by promoting and developing interpreter training, as seen in later publications:

Conflicts can escalate from mere differences to contradictions, polarization, violence and war, and then can de-escalate following a ceasefire designed to pave the way to an agreement, normalization and reconciliation [...] Conflict resolution and subsequent conflict transformation requires negotiation or mediation and the ability of suppressed or marginalized individuals or groups to articulate their interests (Moser-Mercer, 2015, p. 303).

Considering this context, this article aims to bring to this debate a sense of the limits of agency when mediating in such a complex situation: to show how the interpreter's agency is influenced by its embodiment in a conflict and the effects of any act of communication in a multilingual context. "The complex question of agency," it has been argued,

has been considered of primary importance in the endeavour to make descriptive theoretical approaches more "agent-aware" and translators and interpreters more visible as social actors (Inghilleri, 2005, p. 142).

Two main aspects should be observed when defining agency: willingness and ability (Kinnunen \& Koskinen, 2010, pp. 6-7):

1. Willingness describes a particular internal state and disposition. This state is linked to consciousness, reflectivity and intentionality, and it is not without some moral or ethical undertones.

2. Ability relates the concept of agency to constraints and issues of power(lessness), highlighting the intrinsic relation between agency and power [...] Those in subordinate positions may be able to convert their resources, however scant they may be, into some degree of control over their conditions.

As Inghilleri $(2007,2010)$ reflects, the complexity of the interpreter's role relies on the interplay of a number of intersecting realities - historical, cultural, personal and political. Therefore, it remains essential to raise the interpreter's awareness in order to diminish the chances of distorting those perspectives. The realities that influence the war interpreter's agency contribute to determining the scope of their participation. In so doing, the interpreter participates in the elaboration of the range of public narratives of the conflict, "blocking personal narratives and acting as gatekeepers in a variety of respects" (Baker, 2010, pp. 201215).

Claiming a higher level of agency via interpretation could, however, pose major problems. To begin with, once the interpreter chooses not to render the testimony of the original witness faithfully, a violence is undeniably committed against the witness's testimony (Stahuljak, 1999, p. 403). Therefore, the interpreter's agency should always rely on a conscious activism rather than unconscious disruptions in interpreting. In addition, interpreters working for the military will find themselves embedded in certain perspectives with respect to the war within the framework of the military they are working for. In the words of Inghilleri (2010): 
Moreno-Bello, Y. (2021). Narratives in conflict and the limits on the interpreter's agency: A case study from the UN Peacekeeping mission in Lebanon. Linguistica Antverpiensia, New Series: Themes in Translation Studies, 20, 94-114.

Training in military ethics influences the way members of the military understand the purpose of a particular conflict, their role within it, and their behaviour towards their enemies and allies in combat. (p. 180)

In order to observe whether military training might affect the interpreter's autonomy, the article provides this information for each of the interviewees in the corpus. In this way, the definition of the agency of the conflict zone interpreter as a core factor in the making of war and the building of peace is of special interest.

\section{Methodology}

As already mentioned, the main objective of this article is to evaluate the interpreter's agency in their linguistic intervention by classifying interferences that require mediation in certain narrative features in order to argue for further training in the matter of agency in this specific context.

The methodology used to accomplish this objective was implemented as follows:

(1) categorize cultural and linguistic barriers (interferences) in a selection of narrative features developed by Baker (2006) and defined in section 4; and

(2) analyse and interpret the level of agency of each excerpt.

The questions included in the interviews were intended to identify those interferences during communication in conflict zones and their impact on an interpreter's agency. The core of the corpus was excerpted from personal interviews to obtain in-depth insights into interpreters' agency and experiences. A semi-structured interview of 10 open-ended questions was used to initiate the interviews. Follow-up questions were used as the semi-structured interviews followed the natural path of a conversation. This openness led to questions and answers of a diverse nature intended to analyse the interpreter's intervention in aspects related to

- cultural context such as identity, beliefs, superstitions, ideals, values, dogmas;

- specific ideas such as symbolism, ideological representations, characters, romanticisation or demonisation;

- aspects of particular settings such as dialects, accent, tone, dress code; and

- other aspects such as formalities, courtesy manners, hierarchies, register, rules, etc.

In this sample, only the excerpts that contained information relevant to our study were selected. Interviews were conducted in English and Spanish. As a small sample, its findings cannot of course be considered representative; however, the sample provides several indicators for an analysis of the interpreter's perceptions of their operational challenges in the context of conflict zones.

The seven interviews scrutinized for this article were conducted in Beirut and Marjayoun (UNIFIL military base) and were collected from two different groups of interpreters: locally recruited and military. The selected excerpts correspond to interviews interpreted by four locally recruited interpreters and three military interpreters, of whom only two had had formal training in interpreting and translation. These samples include three female 
Moreno-Bello, Y. (2021). Narratives in conflict and the limits on the interpreter's agency: A case study from the UN Peacekeeping mission in Lebanon. Linguistica Antverpiensia, New Series: Themes in Translation Studies, 20, 94-114.

interpreters and four male interpreters between 26 and 45 years of age and of either Lebanese or Spanish nationality. While the locally recruited interpreters worked during the conflicts that occurred in Lebanon in 2006, the three military interpreters worked mainly in civil-military operations. To preserve the ethics of the research, the interviewees provided their verbal agreement to being recorded even though their personal information has remained undisclosed.

\subsection{Model of analysis and interpretation of the data}

I aim to estimate the degree of agency experienced by interpreters working in conflict zones through the analysis of their answers. The data obtained from the interviews allowed me to classify interferences reported by interpreters from their own experiences and to analyse the interpreters' behaviour expressed in each situation - in other words, the degree of agency presented by the interpreter when encountering different interferences. On the one hand, we classified the interpreters' expressed behaviour into the following three levels of agency:

1. Whether the interpreter does not consider it necessary to mediate, i.e., their interpretation is literal, and chooses instead to render the original message faithfully.

2. Whether the interpreter asks for permission to mediate.

3. Whether the interpreter decides to mediate regarding social, religious and political aspects, altering the original message or adding explanations to it.

On the other hand, the theoretical approach to categorizing the interferences proposed in this article was devised considering a limited number of the narrative features developed by Baker (2006) and their articulation in the context of interpreting in conflict zones. In contrast to the breadth and reach of the initial study described in Moreno-Bello (2017), this article focuses only on a selection of the four narrative features most loaded with interferences: "relationality", "particularity", "genericness", and "normativeness" (Baker, 2006) in a deliberate attempt to limit the scope of this article.

As is discussed in section 4, the interferences in this article are seen as indicators of those narrative features. With this perspective in mind, a series of categorizations is proposed through Baker's model in order to determine the ways in which the interferences are perceived in this study (see Table 1). The reason for this categorization is to present a method for evaluating the level of agency of interpreters in relation to narrative features so as to deal with the direct impact of its agency on communication in a conflict situation. This categorization is meant to help us provide a consistent clarification of the choices made during the analysis of the data collected through interviews and to help the reader follow the model we propose.

\section{Narrative theory applied to interpreting in conflict zones}

Following on from Baker's adaptation of narrative theory and a previous study by MorenoBello (2017), Table 1 presents Baker's narrative features in the first column next to her definitions of each; alongside these we juxtapose the linguistic and cultural aspects that characterize the narrative features. The application of Baker's narrative theory will allow us to extrapolate results to any other kind of linguistic and cultural interference and analyse an 
Moreno-Bello, Y. (2021). Narratives in conflict and the limits on the interpreter's agency: A case study from the UN Peacekeeping mission in Lebanon. Linguistica Antverpiensia, New Series: Themes in Translation Studies, 20, 94-114.

interpreter's agency in relation to the context instead of analysing them as anecdotes or isolated events. Accordingly, these components are the focus of the discussion in the examples that follow.

According to this model, we considered two important aspects. On the one hand, the features "particularity" and "relationality" refer to interferences of a more abstract nature. They are related to beliefs of a particular ideology. As explained by Baker (2006, p. 81), these are: "Motifs and skeletal storylines within which the 'particularity' of a narrative is realized, shape our interpretation of events and discourses in other ways". This feature "refers to specific events and people but nevertheless do so within a more general framework of "story types" which give the specific happening their meaning and import". A useful example to help with understanding this feature is the use of a biblical paradox to teach a lesson: the narrative would need to be rephrased when told to someone who is not religious or has never been in touch with any religion, to make it valid and transferable. In this sense, "particularity" could be used as a tool to manipulate identity-based subject positions.

On the other hand, "relationality" "means that it is impossible for the human mind to make sense of isolated events that are not constituted as narrative" (Baker, 2006, p. 170). For this reason, "relationality" is normally used to retell the same story from another point of view (or narrative) in order to fit in the new context, culture or setting in which the event is taking place (see example 5 below).

In contrast, the features "genericness" and "normativeness" are more easily perceptible and are not directly related to beliefs or ideologies, but they correspond to a particular social context or setting. In "genericness",

narratives have to be elaborated within established frameworks to be intelligible, and these frameworks are recognizable kinds of narratives such as: [...] legal contracts, shopping lists, menus, academic articles, magazine interviews, among others (Baker, 2006, p. 85).

In our context it is easy to see the different genres: military vs civilian, religious vs secular, formal vs informal, etc. In addition, "normativeness" "rest[s] on a breach of conventional expectation, centrally concerned with cultural legitimacy". Following or breaching the norm or rules can be observed as respecting or disrespecting the authority, as seen in examples 2 and 8 below. 
Moreno-Bello, Y. (2021). Narratives in conflict and the limits on the interpreter's agency: A case study from the UN Peacekeeping mission in Lebanon. Linguistica Antverpiensia, New Series: Themes in Translation Studies, 20, 94-114.

Table 1. Interferences corresponding to narrative features

\begin{tabular}{|c|c|c|}
\hline $\begin{array}{l}\text { Narrative } \\
\text { features } \\
\text { (Baker, 2006) }\end{array}$ & $\begin{array}{l}\text { Definition } \\
\text { (Baker, 2006, pp. 167-170) }\end{array}$ & $\begin{array}{l}\text { Interferences } \\
\text { (Moreno-Bello, 2017) }\end{array}$ \\
\hline Relationality & $\begin{array}{l}\text { Narrative feature developed by Somers (1992, } \\
\text { 1997) and Somers and Gibson (1994). "Relation- } \\
\text { ality" indicates the impossibility of a human be- } \\
\text { ing making sense of isolated events or remnants } \\
\text { of events that have not been shaped as a narra- } \\
\text { tive. }\end{array}$ & $\begin{array}{l}\text { Aspects related to cul- } \\
\text { tural context: identity, } \\
\text { beliefs, superstitions, } \\
\text { ideals, values, dogmas, } \\
\text { etc. }\end{array}$ \\
\hline Particularity & $\begin{array}{l}\text { According to Bruner's (1991) model, "particular- } \\
\text { ity" means that narratives refer to specific } \\
\text { events and people in stories or narratives with } \\
\text { recurrent motifs that may differ in specific de- } \\
\text { tails across cultures. }\end{array}$ & $\begin{array}{l}\text { Aspects related to spe- } \\
\text { cific ideas: symbolism, } \\
\text { ideological representa- } \\
\text { tions, characters, roman- } \\
\text { ticisation or demonisa- } \\
\text { tion, etc. }\end{array}$ \\
\hline Genericness & $\begin{array}{l}\text { Individual narratives must be developed within } \\
\text { an established narrative framework in order to } \\
\text { be intelligible and effective. These frameworks } \\
\text { provide both the sender and the receiver with } \\
\text { "conventional" and wide models "to facilitate } \\
\text { the hermeneutic task of making sense of human } \\
\text { events" (Bruner, 1991, p. 14). } \\
\text { These frameworks are, in fact, genres, "in the } \\
\text { sense that they are recognizable types of narra- } \\
\text { tives" (Bruner, 1991, p. 14): romance, tragedy, } \\
\text { village, city, military base, etc. }\end{array}$ & $\begin{array}{l}\text { Aspects related to a par- } \\
\text { ticular setting: dialects, } \\
\text { accent, tone, dress code, } \\
\text { etc. }\end{array}$ \\
\hline $\begin{array}{l}\text { Normative- } \\
\text { ness }\end{array}$ & $\begin{array}{l}\text { Bruner (1991) argues that narrative capacity } \\
\text { falls on the breach with conventional expec- } \\
\text { tancy. A breach presupposes a norm. }\end{array}$ & $\begin{array}{l}\text { Aspects related to } \\
\text { norms: formalities, cour- } \\
\text { tesy manners, hierar- } \\
\text { chies, register, rules, etc. }\end{array}$ \\
\hline
\end{tabular}

The relationship between interferences and narrative features represented in Table 1 enables us to identify them in the analysis of the interviews presented in section 5.2. 
Moreno-Bello, Y. (2021). Narratives in conflict and the limits on the interpreter's agency: A case study from the UN Peacekeeping mission in Lebanon. Linguistica Antverpiensia, New Series: Themes in Translation Studies, 20, 94-114.

\section{Analysis of interviews}

The recorded interviews with the seven interpreters were then transcribed preserving, where possible, the characteristics of the oral discourse and therefore maintaining syntactic errors. Only minor alterations were made in order to enable the analysis and comprehension of the excerpts included in this article. To pursue our goal, we identify, first, the linguistic and cultural barriers (interferences) that the interpreters are referring to by indicating the exact sentence with a number between brackets (No.). Second, we categorize the interferences as per the narrative features discussed above. Finally, we determine the level of agency shown by the interpreter in relation to the three-level scale discussed in section 3 . The interferences where the level of agency can be observed are marked in bold in the excerpts.

\subsection{Interview 1: Dialectal variation}

A lack of linguistic competence can result in situations such as a divergence of dialects, accents or ways of speaking. Moreover, while speaking the same language, participants could make linguistic choices that may imply a different meaning from what they actually intended. In the following excerpt, this military interpreter explains her role as a mediator, intervening when a misunderstanding occurs. However, the intervention or mediation might take place after obtaining previous authorization. This shows that the interpreter's agency is restrained by her formal training and her specific commitment to the "contractor". This limitation (1) might therefore provoke a delay in the conversational flow, confusion, and even reduce the credibility of the interpreter if interruptions continue. The tables refer to specific examples taken from the full interview that are available in Moreno-Bello's (2017) doctoral dissertation "Applying language studies to conflict zones: The case of the war interpreter" and are indicated by the number in parenthesis.

\section{Example 1: Dialectal variation}

(1) If they don't use the literary Arabic, if they use their own Arabic [...] If I see there is a misunderstanding, I say: "May I explain what is happening?", and if they say "yes", I will explain it; but won't do it on my own. I will ask first.

\begin{tabular}{|l|l|l|}
\hline Interference: & Narrative feature: & Level of agency: \\
\hline (1) Dialectal variation & Genericness & 2 \\
\hline
\end{tabular}

In this case, the interference (dialectal variation) shows, according to our classification (table 1 ), this interference, which is not part of a culture-specific reference or part of a belief system, but one belonging to a specific place or setting, should be categorized as "genericness". This interpreter shows a level (2) of agency since she asks for permission to mediate. 
Moreno-Bello, Y. (2021). Narratives in conflict and the limits on the interpreter's agency: A case study from the UN Peacekeeping mission in Lebanon. Linguistica Antverpiensia, New Series: Themes in Translation Studies, 20, 94-114.

\subsection{Interview 2: Formalities and courtesy manners}

Formalities and courtesy manners are behavioural requirements. They are accounted for in socio-linguistic and in intercultural communication as clear indicators of the relationship between the speakers participating in a communicative act. When individuals act outside these requirements and expectations of the social norms of politeness, there is a reaction, even a conflict. In the case of peacekeeping missions, where culturally diverse individuals face each other in a tense encounter, conflicts can escalate very rapidly. For this reason, interpreters play a crucial role in keeping participants at ease when mediating across cultures. In the following example, the interviewed locally recruited interpreter had not been formally trained as an interpreter; they had, however, accrued vast experience working in the field. In this case, we can observe the interpreter's decisive approach towards briefing in different formal aspects.

\section{Example 2: Formalities and courtesy manners}

You [need] training, (2) how you go to the tents, how to act, [...] Every camp has a chief, they call him (2) "shaif shhawish" [...] (2) You have to introduce yourself, if the "shawis" doesn't like you, you'll have to leave the camp, (2) to take out your shoes, they offer you tea, if you don't want the tea, you say: "I'm fasting", or I've got diabetes', don't say: "It's disgusting", don't wear a mask, not to show that they are dirty or you disrespect, don't get sanitizer with you, you can do it in the car. iii

\begin{tabular}{|l|l|l|}
\hline Interference: & Narrative feature: & Level of agency: \\
\hline (2) Formalities \& courtesy manners & Normativeness & 3 \\
\hline
\end{tabular}

Following the table, the interference (2) belongs to the kind of cultural and linguistic barriers categorized (formalities and courtesy manners) in the feature "normativeness". As the interpreter considers it necessary to mediate in social aspects, the level of agency given to this excerpt is (3).

\subsection{Interview 3: Ideology and symbolism}

Whether they are passive or active participants in a conflict, individuals tend to follow ideological narratives that maintain a dichotomous order within that conflict. Manojlovic (2010, p. 5) refers to such binary opposition by explaining how contentious narratives maintain divisions and justification of violent actions. In this sense,

conflict becomes polarized, personalized and continually escalates the rhetoric of conflict and the actions of those as the conflict evolves (Manojlovic, 2010, p. 5).

The following examples include specific jargon and rhetorical figures that imply specific ideological dualities in language. Example 3 offers illustrations of political positioning within the Israeli-Palestinian conflict, whereas Example 4 exposes a religious belief and understanding of God. When the interpreter decides to intervene and use these linguistic 
Moreno-Bello, Y. (2021). Narratives in conflict and the limits on the interpreter's agency: A case study from the UN Peacekeeping mission in Lebanon. Linguistica Antverpiensia, New Series: Themes in Translation Studies, 20, 94-114.

strategies, she is negotiating the ideology and avoiding unnecessary confrontations between participants. Example 3 shows how a locally recruited interpreter mediates with full agency (3), prioritizing the need for ideological mediation over the need to obtain the participant's authorization. Example 4 illustrates a situation in which symbolic interferences are at play: this locally recruited interpreter once again decides to intervene without previous authorization.

\section{Example 3: Ideology}

There is specific jargon from the Arab world: (3) "The Israeli enemy", to make clear which side are we taking, or "The occupied Gaza" [...] I never say "Israel", I say "the occupied zones".

\begin{tabular}{|l|l|l|}
\hline Interference: & Narrative feature: & Level of agency: \\
\hline (3) Ideology & Particularity & 3 \\
\hline
\end{tabular}

The jargon shown in Example 3 belongs to specific ideology, therefore it is categorized as "particularity". This excerpt shows how the interpreter mediates with full agency (3), prioritizing the need for ideological mediation over the need to obtain the participant's authorization.

\section{Example 4: Symbolism - epithets and metaphors}

There are certain verbs in Arabic that have specific meaning when used in reference to God, such as (4) "creator", "to appear". Or, for example, "jihad" in the Quran means "internal sacrifice", "temptations".

\begin{tabular}{|l|l|l|}
\hline Interference: & Narrative feature: & Level of agency: \\
\hline (4) Symbolism & Particularity & 3 \\
\hline
\end{tabular}

Epithets and metaphors mentioned in this excerpt indicate a symbolic interference that belongs to the category "particularity". Example 4 illustrates a situation in which symbolic interferences are at play: this locally recruited interpreter once again decides to intervene without previous, showing level (3) of agency.

\subsection{Interview 4: Symbolism}

Negotiating semantic choices poses a great challenge to unprepared interpreters, who could feel tempted to use more equivalent synonyms without considering the ideological, theoretical and practical context in which they are situated. Given the context exposed in the following example, using a synonym for the word "killed" in Arabic might turn into a loss of trust and sympathy between both sides. In this case, the use of "martyr" embellishes the 
Moreno-Bello, Y. (2021). Narratives in conflict and the limits on the interpreter's agency: A case study from the UN Peacekeeping mission in Lebanon. Linguistica Antverpiensia, New Series: Themes in Translation Studies, 20, 94-114.

event and shows adherence to a specific narrative. The term "martyr" has a religious connotation; it is used to refer to someone killed for their religious beliefs. For this reason, the interpreter decides to intervene without previous authorization:

Example 5: Symbolism - euphemism

\begin{tabular}{|c|c|c|}
\hline Interference: & Narrative feature: & Level of agency: \\
\hline (5) Symbolism & Relationality & 3 \\
\hline
\end{tabular}

The need to mediate regarding religious and political aspects altering the original message also shows a level (3) of agency. In this case, the interpreter was locally recruited.

\subsection{Interview 5: Protocols, beliefs and register}

Example 6 comes from an interview in which we found several interferences that could be categorized as three different narrative features: "genericness", "normativeness", and "relationality". This military interpreter shows different levels of agency. This example illustrates how the lack of a veil is considered disrespectful due to the differing beliefs: the encounter is between an imam and a Muslim woman.

Example 7 portrays a different yet equally disciplined and protocolled setting: the interpreter not only indicates her commitment to her employer, but also displays the limitations that military protocols imply over her work. As the interpreter has to follow a strict protocol, this implies a lack of agency.

Example 8 illustrates the way the register of the participants requires intercultural mediation. Several aspects influence the change of register: hierarchy, gender and age. Not only is the interpreter rendering the message for an authority (mayor) but the fact that she is a young woman affects the way she is supposed to communicate with him. In this case, the interpreter is not invisible: she is part of the conversation and has to obey the rules of the context she is in. 
Moreno-Bello, Y. (2021). Narratives in conflict and the limits on the interpreter's agency: A case study from the UN Peacekeeping mission in Lebanon. Linguistica Antverpiensia, New Series: Themes in Translation Studies, 20, 94-114.

\section{Example 6: Beliefs}

They didn't brief me before [...] so, there was an imam a bit uptight, a priest of the Shi'a community. I went to the interview to interpret but (6) I didn't wear a veil. As a Lebanese/Muslim woman, we know that if we have an interview with a religious person and I have to be there, I have to wear a veil.

So, he said:

- "Why do you come like this to my house? You are not wearing a veil, you scoundrel!" He disrespected me and I stayed for my job. I am Muslim, is true, but no one can force me to wear a veil. To reduce the tension and to avoid giving him a reason to get angry at the Spanish soldiers, I said:

- "You are right, next time I will wear the veil; I am very sorry. Please, accept my apologies."

So, one soldier said: "If you want, she can leave, and we will bring another interpreter."

\begin{tabular}{|l|l|l|}
\hline Interference: & Narrative feature: & Level of agency: \\
\hline (6) Beliefs & Relationality & 3 \\
\hline
\end{tabular}

As a perceptible interference that is related to the cultural context, this indicator is categorized as "relationality". The interpreter intervenes regarding religious aspects, showing level (3) of agency. In this case, the need to mediate seems very obvious to the interpreter and her status as military interpreter doesn't restrain her agency.

\section{Example 7: Military protocol}

The military is different to civilians. The military is strict, (7) there are protocols to obey and specific language. We get used to it. Here people are used to it.

\begin{tabular}{|l|l|l|}
\hline Interference: & Narrative feature: & Level of agency: \\
\hline (7) Military protocol & Genericness & 1 \\
\hline
\end{tabular}

This example shows a strict military protocol, which corresponds to a specific setting and therefore example 7 is categorized as "genericness". In this case, the interpreter indicates not only a commitment to her contractor, but the limitations that military protocols imply over her work. As the interpreter has to follow a strict protocol, this implies a lack of agency, corresponding to level (1). However, this statement does not correspond to her other statements in which she shows level (3) of agency. 
Moreno-Bello, Y. (2021). Narratives in conflict and the limits on the interpreter's agency: A case study from the UN Peacekeeping mission in Lebanon. Linguistica Antverpiensia, New Series: Themes in Translation Studies, 20, 94-114.

\section{Example 8: Register}

I try to help them to understand different aspects, because the Spanish soldiers come from another culture and don't know what is normal [...] They swear in a friendly or informal manner: (8) "iEra un cabrón!" [...] In Arabic that sounds awful. It's very difficult as an interpreter, also as a young girl, interpreting between an older mayor and a Spanish soldier. He wouldn't accept a word like that from me. So, as a matter of respect, like between a father and his daughter, even if I am the interpreter ... Because between men and women is not the same.

\begin{tabular}{|l|l|l|}
\hline Interference: & Narrative feature: & Level of agency: \\
\hline (8) Register & Normativeness & 3 \\
\hline
\end{tabular}

Swearing can be considered as a sign of informality, either offensive or friendly, depending on the setting and the culture. For this reason, this interference is categorized as "normativeness". In this case, the interpreter is not invisible, she is part of the conversation and has to obey by the rules of the context she is in. By altering the message or avoiding some parts, this military interpreter shows level (3) of agency.

\subsection{Interview 6: Particular settings}

The cultural context in which individuals are placed will dictate their mindset to perceive certain interactions as offensive or cordial and doing so will help to build or lose trust among them. In Example 9, it is clear that the interpreter is aware of the risks of interpreting utterances that belong to different settings, but he is limited by his commitment to his employer, unwilling to modify the content under any circumstances.

\section{Example 9: Setting}

It is very important at a cultural level that you understand the Arabic culture, how they think, and how things work. If you ignore that knowledge, the message loses meaning. (9) If I tell you an Arabic joke, it might be very funny for Arabs but might not be for Spanish people. If someone needs to take a decision, culture influences a lot [...] So if it doesn't affect the meaning, I will make the change, but only if the content doesn't change [...] At the end, you have to find a moment and show the authority why you said what you said, and they appreciate it.

\begin{tabular}{|l|l|l|}
\hline Interference: & Narrative feature: & Level of agency: \\
\hline (9) Setting & Genericness & 1 \\
\hline
\end{tabular}


Moreno-Bello, Y. (2021). Narratives in conflict and the limits on the interpreter's agency: A case study from the UN Peacekeeping mission in Lebanon. Linguistica Antverpiensia, New Series: Themes in Translation Studies, 20, 94-114.

In this case, the interpreter does not specify many cultural interferences (apart from telling jokes and taking decisions). Here, instead, the military interpreter shows level (1) of agency, since the interpreter would modify cultural interferences only if they do not affect the content. Since it belongs to a very specific setting, it is categorized as "genericness".

\subsection{Interview 7: Beliefs}

In critical contexts vocabulary may be a trigger of potential conflict. Example 10 shows how linguistic choices can affect communication and trust between participants. In this case, the interpreter is greatly concerned about synonyms and their nuances. In this case, the use of "Shaytan" is a false friend of "Eblees" since it implies a pejorative meaning that the original message did not possess.

\section{Example 10: Beliefs}

Cultural differences once caused a problem with some religious Iraqi minorities' representatives when another colleague translated the word (10) Satan (Eblees in Arabic) into (Shaytan), which is equivalent to devil. Participants were so much offended later we knew that "Shaytan" is culturally and religiously offensive. Other occasions where participants show off their powers in the language, they use it in a way that gets them not to respect the fact that there are no total synonyms, i.e., a word in the target language that is $100 \%$ identical to another word in the source language.

\begin{tabular}{|l|l|l|}
\hline Interference: & Narrative feature: & Level of agency: \\
\hline (10) Beliefs & Relationality & 3 \\
\hline
\end{tabular}

This locally recruited interpreter also added "there is no total synonyms" and gave examples of how some words might have different meanings depending on the culture they belong to and have a different impact on the participants as a result. For this reason, the interpreter shows a level (3) of agency. As a narrative feature, this religious interference falls within "relationality".

As explained in this section, this article has included some examples to show that there are different levels of agency which interpreters acquire depending on the type of situation they might be involved in and their own perspective on a matter. In order to synthesize the findings mentioned in the previous section, the levels of agency identified during the analysis of the selected excerpts of interviews have been grouped according to their features and included in Table 2. 
Moreno-Bello, Y. (2021). Narratives in conflict and the limits on the interpreter's agency: A case study from the UN Peacekeeping mission in Lebanon. Linguistica Antverpiensia, New Series: Themes in Translation Studies, 20, 94-114.

Table 2. Interpreter's level of agency categorized by features (own elaboration)

\begin{tabular}{|l|l|}
\hline Feature & Levels of agency \\
\hline Relationality & $3-3-3$ \\
\hline Particularity & $3-3$ \\
\hline Genericness & $2-1-1$ \\
\hline Normativeness & $3-3$ \\
\hline
\end{tabular}

The interferences found in the previous examples correspond to different linguistic and cultural barriers or interferences categorized as follows. First, under the feature "relationality" we categorized cultural interferences such as beliefs, that is, cultural interferences directly related to a specific cultural context. The interpreters use strategies that show an average of level (3) agency in their reaction to the given circumstances. Secondly, under the feature "particularity" interferences such as symbolism and ideology were categorized. For these types of interference, the interpreter also showed a high level (3) of agency. Third, under the feature "genericness" we identified dialects, military protocols and other characteristic of specific settings, and how they interfered during interpreting. The interpreters had an average of level (1) agency. Finally, under the feature "normativeness", interferences such as register, formalities and courtesy manners and were identified as displaying a higher level of agency (3).

\section{Discussion}

By its nature, the interpretation of the interview replies made this study subjective; the sensitivity of the topic further complicated the approach to achieving a distanced, poised and detached interpretation of the data for it to be usable in other research or in future projects for validation on a larger scale than the findings of this study. These conditions posed great challenges for this research. However, a specific guideline was followed orientating it clearly towards new processes that could be used in order to improve quality and maximize efficiency and academic rigour. Towards this end, this research provided a methodology based on qualitative analysis. In general, the strategies used by the interpreters towards each of the different features in the narrative in conflict were used to create rapport and to ensure that each interaction followed the cultural norms applicable to social encounters in this specific context. However, the findings from the analysis of the interviews show different levels of agency considering different narrative features. The replies under the narrative feature "normativeness" indicate that interpreters have high agency and tend to mediate when they understand that interpreting literally might be a breach of the norm in the target's context. The replies categorized under the narrative feature "genericness" suggest a lack of mediation when encountering explicit interferences, or at least that interpreters seem to require prior authorization. It seems, therefore, that in these types of extreme situation the 
Moreno-Bello, Y. (2021). Narratives in conflict and the limits on the interpreter's agency: A case study from the UN Peacekeeping mission in Lebanon. Linguistica Antverpiensia, New Series: Themes in Translation Studies, 20, 94-114.

variability of the interferences involved, according to the setting and its social characteristics, may have a direct impact on and limit the interpreters' agency. In this specific case, military deployment as a genre might be imposed as a part of the job. Therefore, further and specific training in order to avoid the occurrence of a static interpreter seems to be relevant in this context. At the same time, this often occurs when the interpreter is part of the narrative itself, and especially when the interpreter is forced to act within a specific narrative. Specifically in this study, three of the five examples given by military interpreters showed a lower degree of agency.

On the other hand, features such as "particularity" and "relationality" indicate that the interpreter's agency is not necessarily restrained. This implies that the interpreter possesses sufficient autonomy to mediate when they notice cultural differences, interferences in storylines or different points of view, rather than those that belong to a specific genre. This shows that even though the interpreters remained detached from their own religious, cultural or political narrative, they were not able to detach themselves from their contractor. Regarding training, this is attributable to the contractor's lack of attention to the military interpreter's autonomy.

Data gathered through this method confirmed a duality concerning the interpreter's agency. Although most interpreters involved in the project agreed about the need to mediate when cultural interferences or misunderstandings are involved, they did not agree about the specific circumstances in which modifying the content is required. In order to avoid difficulties, some of them preferred to be literal or, in any case, to summarize the content. We may say that the greater their awareness of their role as mediators, the more agency they would display; however this was not always the case. It is worth noting that Todorova (2016) also found in her study that:

Most interpreters believed that interpreters should indeed remain invisible yet at the same time most also believed the interpreter did have a crucial role to play in conflict mediation. That would indicate that while they may be intuitively aware of their agency in the mediation process, the dominant education narrative still works to cancel that out. (p. 238)

Such a dichotomy is often at play in similar contexts, as observed by Gómez-Amich (2018, p. 37), whose subjects in the study "interpreting in conflict zones" showed higher levels of agency and latitude in comparison those in other interpretation settings, even though they were restricted by military protocols. She argued that the main reason was that these types of interpreter were "used" as intelligence sources, and therefore contractors relied on their capacity to judge situations.

\section{Conclusions}

The study discussed in this article focused specifically on the ways in which the interpreters' perspectives manifest themselves towards cultural interferences in the interlinguistic communication between the military and the civilian population. It aimed to analyse and reflect on the level of agency that interpreters in military deployments have, depending on their operational circumstances and their impact on communication. It intended to explore the notion of agency, vis-à-vis the cultural interferences that require the mediation of specific 
narrative features (discussed in section 3.1). The theoretical model proposed, and the categories developed, helped this researcher to determine the extent to which the interpreter makes decisions regarding their intervention and the perception of their role regarding that specific narrative feature. The interpreters interviewed considered necessary to mediate when interpreting in relation to cultural interferences and misunderstandings in a given context. Only in the case of "genericness", did the lack of agency contrast with and hinder the mediating work that the interpreter considered necessary.

The results of this study indicate the ways in which the interpreters who participated were able to mediate towards "normativeness", "relationality" and "particularity". The study also reveals that they struggled with "genericness", as the type of genre they were embedded in was a militarized context, one especially limited by their contractor's agenda. It is indeed this type of context that makes mediation more complex, as observed in examples 1, 7 and 9. Therefore, training in military deployments should empower interpreters to acquire the necessary autonomy for this type of context. It could be argued, however, that the sample considered here may not be representative. Nevertheless, the results of the data gathered are understandable and indicate a greater need for training for military settings; they also emphasize the interpreter's agency and their ability to discern the level of mediation required in certain interventions. Ultimately, the specific practice that this profession implies is the need for acute awareness of both the mediation process required and its limitations. 
Moreno-Bello, Y. (2021). Narratives in conflict and the limits on the interpreter's agency: A case study from the UN Peacekeeping mission in Lebanon. Linguistica Antverpiensia, New Series: Themes in Translation Studies, 20, 94-114.

\section{References}

Angelelli, C. V. (2003). The interpersonal role of the interpreter in cross-cultural communication: A survey of conference, court and medical interpreters in the US, Canada and Mexico. In L. Brunette, G. L. Bastin, I. Hemlin, \& H. Clarke (Eds.), The Critical Link 3: Interpreters in the community. Selected papers from the Third International Conference on Interpreting in Legal, Health and Social Service Settings (pp. 15-26). John Benjamins. https://doi.org/10.1075/btl.46.06ang

Angelelli, C. V. (2004). Medical interpreting and cross-cultural communication. Cambridge University Press. https://doi.org/10.1017/CBO9780511486616

Baker, M. (2006). Translation and conflict: A narrative account. Routledge. https://doi.org/10. $\underline{4324 / 9780203099919}$

Baker, M. (2010). Interpreters and translators in the war zone: Narrated and narrators. The Translator, 16(2), 197-222. https://doi.org/10.1080/13556509.2010.10799469

Bruner, J. (1991). The narrative construction of reality. Critical Inquiry, 18(1), 1-21. https://doi.org/ $\underline{10.1086 / 448619}$

Federici, F., \& O'Brien, S. (Eds.). (2019). Translation in cascading crisis. Routledge. https://doi. org/10.4324/9780429341052

Gómez-Amich, M. (2018) Life in conflict: A series of narratives by locally recruited interpreters from Afghanistan. Close Encounters in War Journal, (1), 22-44, Special Issue: "Close encounters in irregular and asymmetric warfare".

Hall, E., \& Hall, T. (1959). The silent language. Anchor books.

Hoedemaekers, I., \& Soeters, J. (2009). Interactions rituals and language mediation during peace missions: Experiences from Afghanistan. In C. Caforio (Ed.), Advances in military sociology: Essays in honour of Charles C. Moskos (pp. 329-352). Emerald Group. https://doi. org/10.1108/S1572-8323(2009)000012A024

Inghilleri, M. (2005). The sociology of Bourdieu and the construction of the 'object' in translation and interpreting studies. The Translator, 11(2), 125-145. https://doi.org/10.1080/1355 $\underline{6509.2005 .10799195}$

Inghilleri, M. (2007). National sovereignty versus universal rights: Interpreting justice in a global context. Social Semiotics, 17(2), 195-212. https://doi.org/10.1080/10350330701311488

Inghilleri, M. (2010). You don't make war without knowing why, The Translator, 16(2), 175-196. https://doi.org/10.1080/13556509.2010.10799468

Katan, D. (2009). Translation as intercultural communication. In J. Munday (Ed.), The Routledge companion to translation studies (pp. 74-92). Routledge.

Kinnunen, T., \& Koskinen, K. (2010). Translators' agency. Tampere University Press.

Manojlovic, B. (2010). Dealing with complexities of identity conflict: Contentious narratives and possibilities of their transformation. Human Security Perspectives, 7(1), 1-16.

Moreno-Bello, Y. (2017). Aplicación de estudios sobre el lenguaje en zonas en conflicto: El caso del intérprete de guerra [Applying language studies to conflict zones: the case of the war interpreter]. [Unpublished doctoral dissertation]. University of Alcalá.

Moreno-Bello, Y. (2021). Negotiating ideologies in conflict zones: The case of the interpreter in Lebanon. In M. Todorova \& L. Ruiz Rosendo (Eds.), Interpreting conflict: A comparative framework (pp. 113-133). Palgrave Macmillan. https://doi.org/10.1007/978-3-030-66909-6 6

Moser-Mercer, B., Kherbiche, L., \& Class, B. (2014). Interpreting conflict: Training challenges in humanitarian field interpreting. Journal of Human Rights Practice, 6(1), 140-158. https://doi.org/10.1093/jhuman/hut025

Moser-Mercer, B. (2015). Interpreting in conflict zones. In H. Mikkelson \& R. Jourdenais (Eds.), The Routledge handbook of interpreting (pp. 302-316). Routledge.

Nida, E. (2001). Contexts in translating. Amsterdam. John Benjamins. https://doi.org/10.1075/btl.41 
Moreno-Bello, Y. (2021). Narratives in conflict and the limits on the interpreter's agency: A case study from the UN Peacekeeping mission in Lebanon. Linguistica Antverpiensia, New Series: Themes in Translation Studies, 20, 94-114.

Pöchhacker, F. (2008). Interpreting as mediation. In C. Valero-Garcés \& A. Martin (Eds.), Crossing borders in community interpreting: Definitions and dilemmas (pp. 9-26). John Benjamins. https://doi.org/10.1075/btl.76.02poc

Ruiz Rosendo., L., \& Persaud, M. C. (2018). On the frontline: Mediating across languages and cultures in peacekeeping operations. Armed Forces \& Society, 45(3), 472-490. https:// doi.org/10.1177/0095327X18755108

Somers, M. (1992). Narrativity, narrative identity, and social action: Rethinking English working-class formation. Social Science History, 16(4), 591-630. https://doi.org/10.1017/S014555320 $\underline{0016679}$

Somers, M. (1997). Deconstructing and reconstructing class formation theory: Narrativity, relational analysis, and social theory. In J. Hall (Ed.), Reworking class Ithaca (pp. 73-105). Cornell University Press.

Somers, M., \& Gibson, G. (1994). Reclaiming the epistemological 'other': Narrative and the social construction of identity. In C. Calhoun (Ed.), Social theory and the politics of identity (pp. 37-99). Blackwell.

Stahuljak, Z. (1999). The Violence of neutrality: Translators in and of the war [Croatia, 1991-1992]. College Literature, 26(1), 34-51.

Taft, R. (1981). The role and personality of the mediator. The Mediating Person: Bridges between Cultures, 53-88.

Todorova, M. (2016). Interpreting conflict mediation in Kosovo and Macedonia. Linguistica Antverpiensia, New Series: Themes in Translation Studies, 15, 227-240. https://doi.org/ $10.52034 /$ lanstts.v0i15.392

Wadensjö, C. (2008). In and off the Show: Co-constructing 'invisibility' in an interpreter mediated talk show interview. META, 53(1), 184-203. https://doi.org/10.7202/017982ar

i The project began as a funded international doctoral study carried out at the University of Alcalá, Madrid, Spain, and Saint Joseph University, Beirut, Lebanon.

ii Further information can be found at: https://emad.defensa.gob.es/en/operaciones/21ONU-UNIFIL-Libano/index.html? locale=en

iii Note that the sample was collected in 2016 and the use of masks and sanitizers was not related to Covid-19. 